\title{
Low-molecular-weight fucoidan regulates myogenic differentiation through the mitogen-activated protein kinase pathway in $\mathrm{C} 2 \mathrm{C} 12$ cells
}

\author{
Kui-Jin $\mathrm{Kim}^{1}$, Ok-Hwan Lee ${ }^{2}$ and Boo-Yong Lee ${ }^{1,3 *}$ \\ ${ }^{1}$ Department of Biomedical Science, CHA University, Kyonggi 463-836, Republic of Korea \\ ${ }^{2}$ Department of Food Science and Biotechnology, Kangwon National University, Chunchon 200-701, Republic of Korea \\ ${ }^{3}$ Department of Food Science and Biotechnology, CHA University, 222 Yatap, Bundang, Seongnam, Kyonggi 463-836, \\ Republic of Korea
}

(Received 28 January 2011 - Revised 30 March 2011 - Accepted 5 April 2011 - First published online 20 June 2011)

\section{Abstract}

Low-molecular-weight fucoidan (LMWF) has been broadly studied in recent years due to its numerous biological properties. Nevertheless, there have been no reports about the effects of LMWF on myogenic differentiation (MyoD). The objective of the present study was to demonstrate the impact of LMWF on myogenesis in C2C12 cells. The ultimate aim was to establish whether LMWF regulates myogenesis similar to heparin as a partial regulator of myogenesis. LMWF was prepared at a minimal size by ultra-filtration compared with crude fucoidan. We treated $\mathrm{C} 2 \mathrm{C} 12$ cells with LMWF and/or heparin during MyoD. The data from the present study are the first to suggest that LMWF suppresses the expression of the myogenic regulatory factors and the myocyte enhancer factors as well as the morphological changes that occur during differentiation. Additionally, the expression of the mitogen-activated protein kinase (MAPK) family was significantly inhibited by LMWF when compared with controls. The LMWF-treated group showed significantly decreased expression of reactive oxygen species (ROS) enzymes compared with control cells. Heparin was used as a positive control because it has been reported to activate MyoD. Taken together, these results suggest that LMWF might regulate MyoD through the MAPK pathway and by regulating ROS activity in C2C12 cells.

Key words: Fucoidan: Low-molecular-weight fucoidan: Mitogen-activated protein kinase pathway: Myogenic differentiation: Myogenesis

In eukaryotic cells, the p38 mitogen-activated protein kinase (MAPK) signalling pathway, which was originally shown to be activated by environmental stress and pro-inflammatory cytokines, is a component of several important signalling pathways that relay extracellular cues to transcription factors in the nucleus ${ }^{(1-3)}$. The MAPK family primarily consists of three subfamilies: p38 MAPK $\alpha$; extracellular-regulated kinase (ERK); Jun $\mathrm{NH}_{2}$-terminal kinase (JNK). These pathways are known to have an important role in the development of skeletal muscle ${ }^{(4-6)}$.

Myogenesis is a multistep process in which myoblasts cease to divide, elongate and fuse into multinucleated myotubes. The cellular changes include elongation, polarisation, aggregation and fusion and ultimately give rise to functional muscle. Myogenesis involves two families of transcription factors. One family is the myogenic regulatory factors (MRF), which include myogenic differentiation (MyoD), myogenic factor 5, myogenic regulatory factor 4 (MRF4) and myogenin $^{(7-9)}$. MRF are skeletal muscle-specific transcription factors. The other family is the myocyte enhancer factors (MEF) and includes MEF2A, B, C and D. The MRF and the MEF contribute to myogenesis by binding to regions within the promoters of muscle-specific genes ${ }^{(8)}$.

Reactive oxygen species (ROS) function as secondary messengers for the signal transduction induced by many cytokines and contribute to proliferation and differentiation $^{(10,11)}$. It has been shown that both exogenous and endogenous ROS activate the MAPK pathway ${ }^{(12,13)}$. Several studies have shown that low ROS concentrations enhance the growth of many types of mammalian cells via MAPK activation, which is often associated with proliferation and differentiation $^{(14,15)}$

Since the identification of fucoidan, it has been broadly studied for its numerous biological properties ${ }^{(16-20)}$.

Abbreviations: DMEM, Dulbecco's modified Eagle's medium; ERK, extracellular-regulated kinase; JNK, Jun $\mathrm{NH}_{2}$-terminal kinase; LMWF, low-molecularweight fucoidan; MAPK, mitogen-activated protein kinase; MRF, myogenic regulatory factor; MRF4, myogenic regulatory factor 4; MyoD, myogenic differentiation; OD, optical density; ROS, reactive oxygen species; XTT, sodium 3'-[1-[(phenylamino)-carbonyl]-3,4-tetrazolium]-bis (4-methoxy-6nitro)benzene sulfonic acid hydrate.

* Corresponding author: Professor B.-Y. Lee, fax +82 31725 8350, email bylee@cha.ac.kr 
Fucoidan, a sulfated polysaccharide, is primarily extracted from brown seaweeds such as Fucus vesiculosus, Ecklonia kurome and Undaria pinnatifida. It consists of L-fucose, together with xylose, galactose and mannose ${ }^{(21-23)}$. Some of the effects of fucoidan on smooth muscle proliferation have been reported to involve the p38 MAPK pathway ${ }^{(24)}$, but the detailed biological effects of low-molecular-weight fucoidan (LMWF) on ROS production, the expression of MRF and p38 MAPK-mediated signalling during MyoD and ROS have not been thoroughly investigated. Fucoidan preparations have been proposed as an alternative to the anticoagulant heparin. As with heparin, it has been shown that fucoidan affect many biological activities, such as anticoagulation, inflammation, cell proliferation and adhesion ${ }^{(25)}$. However, we use heparin as a negative control in the present study.

In the present study, the potential effects of LMWF on muscle differentiation were examined in vitro by analysing the effects of LMWF on gene expression and protein activity during myoblast differentiation into myotubes.

\section{Materials and methods}

\section{Materials}

Dulbecco's modified Eagle's medium (DMEM), fetal bovine serum, horse serum, PBS and trypsin-EDTA were acquired from Gibco (Gaithersburg, MD, USA). Penicillin-streptomycin was purchased from JBI (Daegu, Chungchengnamdo, South Korea). Fucoidan was provided by Heawon Company, Inc. (Seoul, South Korea) and has been shown to be non-toxic by toxicity tests ${ }^{(14,26)}$. It was hydrolysed by the method of Nardella et $a l .{ }^{(27)}$ to produce LMWF. Heparin was purchased from Sigma (St Louis, MO, USA). The RNAlater was purchased from Ambion (Austin, TX, USA). Total RNA extraction and purification were done using the QIAGEN RNeasy Mini Kit (Qiagen, Hilden, Germany). The First-Strand cDNA Synthesis Kit and Taq DNA polymerase were obtained from Invitrogen (Carlsbad, CA, USA) and Solgent (Daegeon, Chungchengnamdo, South Korea), respectively. Primers were supplied by Bioneer (Daejon, Chungchengnamdo, South Korea).

\section{Cell culture}

Myotubes were cultured from the murine skeletal musclederived C2C12 myoblast line from American Type Culture Collection (Rockville, MD, USA) as described previously ${ }^{(28)}$. Briefly, C2C12 cells were cultured in DMEM supplemented with $10 \%$ fetal bovine serum and $1 \%$ penicillin and streptomycin at $37^{\circ} \mathrm{C}$ in the presence of $5 \% \mathrm{CO}_{2}$. MyoD was initiated by replacing the growth medium with differentiation medium (DMEM supplemented with $2 \%$ horse serum). This medium was then replaced every day. Differentiation was allowed to continue for $72 \mathrm{~h}$ before the addition of LMWF. To investigate the effects of LMWF on MyoD, LMWF concentrations of $0,1,10$ and $100 \mu \mathrm{g} / \mathrm{ml}$ were applied to the cells. The same concentrations of LMWF were added at $24 \mathrm{~h}$ intervals when the culture medium was replenished. Cells left untreated with LMWF were used as controls in these experiments.

\section{Cell viability}

Cell viability was determined using a sodium $3^{\prime}-[1-[($ phenylamino)-carbonyl]-3,4-tetrazolium]-bis (4-methoxy-6-nitro)benzene sulfonic acid hydrate (XTT) reduction assay according to the method described by Roehm et al. ${ }^{(29)}$. The tetrazolium salt XTT used in the colorimetric proliferation assay was purchased from Sigma (Taufkirchen, Germany). Briefly, exponentially growing cells were plated in ninety-six-well microplates at a density of $1 \times 10^{4}$ cells/well in the DMEM/fetal bovine serum medium and then incubated at $37^{\circ} \mathrm{C}$ under $5 \%$ $\mathrm{CO}_{2}$ for $48 \mathrm{~h}$ before the treatment. Cells were then treated with various concentrations of LMWF after which the absorbance was measured at $570 \mathrm{~nm}$ using an ELISA reader (Bio-Tek Instruments, Winooski, VT, USA). All measurements were collected five times ( $n$ ) , and the effect of LMWF on cell viability was assessed by calculating the optical density (OD) values at $570 \mathrm{~nm}$ for the LMWF-treated samples as a percentage of control values.

\section{RNA isolation and semi-quantitative RT-PCR}

Total RNA was extracted from C2C12 cells using the Qiagen RNeasy Kit (Qiagen, Valencia, CA, USA). RNA samples with an $\mathrm{OD}_{260} / \mathrm{OD}_{280}$ ratio greater than $2 \cdot 0$ were used for semiquantitative RT-PCR. Total RNA $(1 \mu \mathrm{g})$ was used to produce CDNA in an RT-PCR system. The sequences of the oligonucleotide primers were as follows: GAPDH sense ( $5^{\prime}$-AACTTTGGCATTGTGGAAGG- $3^{\prime}$ ) and antisense (5'-ACACATTGGGGGTAGGAACA- $3^{\prime}$ ); p38 MAPK $\alpha$ sense (5'-CCTTGACCAAGAAGAAATG- $\left.3^{\prime}\right)$ and antisense (5'-ACAGACGAACAGACAGACAC- $\left.3^{\prime}\right)$; ERK sense (5'-GCTCACCCTTACCTGGAACA- $\left.3^{\prime}\right)$ and antisense (5'-GGACCAGATCCAAAAGGACA- $\left.3^{\prime}\right)$; JNK sense $\left(5^{\prime}\right.$-AATGGTTTGCCACAAAATCC- $\left.3^{\prime}\right)$ and antisense $\left(5^{\prime}\right.$ GAGTCAGCTGGGAAAAGCAC- $3^{\prime}$ ); myogenin sense ( $5^{\prime}$-CAGGAGGAGCGCGATCTCCGCTAC- $3^{\prime}$ ) and antisense (5'-CAGAAGTGATGGCTTTGACACCA-3'); MRF4 sense (5'-ATGGACCTTTTTGAAACTGGCTCC- $\left.3^{\prime}\right)$ and antisense (5'-CTGACCTGGGCAGTCGGGTGGCTG-3'); MnSOD sense (5'-GCACCACAGCAAGCACCAT $\left.-3^{\prime}\right)$ and antisense (5'- TGTCCCCCACCATTGAACT$3^{\prime}$ ); glutathione reductase sense (5'-GGGCAAGGTGCTGCTCATTG-3') and antisense ( $5^{\prime}$-AGAGCGGGTGAGCCTTCTCA$\left.3^{\prime}\right)$; glutathione peroxidase (GPx) sense (5'-CTCGGTTTCCCGTGCAATCAG- $3^{\prime}$ ) and antisense (5'- GTGCAGCCAGTAATCACCAAG- $3^{\prime}$ ); catalase sense (5'-TCTGCAGATACCTGTGAACTG$\left.3^{\prime}\right)$ and antisense (5'-TAGTCAGGGTGGACGTCAGTG- $3^{\prime}$ ). The PCR products were run on $1.0 \%$ agarose gels, stained with ethidium bromide and photographed. Expression levels were quantified by scanning the gels and using an analysis system (Vilber Lourmat, GI-070AP, Marne la Vallée, France).

\section{Western blot analysis}

Cells were collected in lysis buffer (50 mm-4-(2-hydroxyethyl)1-piperazineethanesulfonic acid, $137 \mathrm{~mm}-\mathrm{NaCl}, 1 \mathrm{~mm}-\mathrm{MgCl}_{2}$, 
$1 \mathrm{~mm}^{-\mathrm{CaCl}_{2},} 10 \mathrm{~mm}-\mathrm{Na}_{2} \mathrm{P}_{2} \mathrm{O}_{7}, \quad 10 \mathrm{~mm}-\mathrm{NaF}, \quad 2 \mathrm{~mm}-\mathrm{EDTA}, \quad 10 \%$ glycerol, $1 \%$ Igepal CA-630, 2 mm-vanadate, leupeptin $(10 \mathrm{mg} / \mathrm{ml})$, aprotinin $(10 \mathrm{mg} / \mathrm{ml})$ and $2 \mathrm{~mm}$-phenylmethylsulfonyl fluoride, $\mathrm{pH} 7 \cdot 4$ ). After lysis, the lysates were clarified by centrifugation at $12000 \mathrm{~g}$ for $20 \mathrm{~min}$ at $4^{\circ} \mathrm{C}$; the protein concentration in the supernatants was determined using the Bradford Protein Assay (Bio-Rad Laboratories, Hercules, CA, USA). Proteins were directly solubilised in Laemmli sample buffer. Equal amounts of protein were separated by SDSPAGE and were transferred to Immobilon-P membranes. Membranes were blocked overnight at $4^{\circ} \mathrm{C}$ and incubated with the indicated antibody for $2 \mathrm{~h}$ at room temperature. Specifically bound primary antibodies were detected with a peroxidase-coupled secondary antibody and enhanced chemiluminescence (Amersham Biosciences, NJ, USA).

\section{Statistical analysis}

All measurements are expressed as means and standard deviations. The results were statistically analysed by a one-way ANOVA followed by the Duncan multiple comparison test. Statistical significance was accepted at a level of $P<0.05$ (SAS Institute, Inc., Cary, NC, USA).

\section{Results}

\section{Cell morphology and viability of C2C12 myotubes}

To determine the effects of LMWF on morphology and MyoD, C2C12 myoblasts were treated for $72 \mathrm{~h}$ with increasing concentrations of LMWF $(0,1,10$ and $100 \mu \mathrm{g} / \mathrm{ml})$ in the growth media. As shown in Fig. 1, increasing the concentration of LMWF led to increased disturbances in the morphology and MyoD of C2C12 cells. XTT was used to determine the cytotoxicity of LMWF in C2C12 myoblast cells. According to the test results, the different concentrations of LMWF had no significant effect on cell viability after 12, 24 and $48 \mathrm{~h}$ incubation periods (Fig. 2). The absorbance values obtained in basal (without LMWF) culture media were set at 100\%, and the mean cell viability values obtained after the LMWF treatment were $97 \cdot 3,93.8$ and $93.7 \%$ of the basal values at LMWF concentrations of 1,10 and $100 \mu \mathrm{g} / \mathrm{ml}$, respectively, after $48 \mathrm{~h}$ of incubation. Thus, we demonstrated that LMWF had no cytotoxic effect over the entire concentration range up to $100 \mu \mathrm{g} / \mathrm{ml}$.

\section{Effects of low-molecular-weight fucoidan on the key genes involved in myogenic differentiation}

We tested the effects of LMWF on the differentiation of $\mathrm{C} 2 \mathrm{C} 12$ myoblasts. C2C12 cells were differentiated in 2\% horse serum medium containing DMEM with LMWF at concentrations of 0 , 1,10 and $100 \mu \mathrm{g} / \mathrm{ml}$. The differentiation medium was replaced every $24 \mathrm{~h}$, and cells were further incubated for $72 \mathrm{~h}$. Expression of the myogenic markers myogenin and MRF4, which are crucial for muscle development, was then examined. RT-PCR analysis revealed that the mRNA expression of myogenin and MRF4 was induced during myogenesis when the $\mathrm{C} 2 \mathrm{C} 12$ cells became fully differentiated; however, this induction was eliminated in the presence of LMWF. LMWF at concentrations of 1,10 and $100 \mu \mathrm{g} / \mathrm{ml}$ decreased the expression of myogenin during the MyoD of C2C12 cells by approximately $5 \cdot 18,11.9$ and $19.4 \%$, respectively, compared
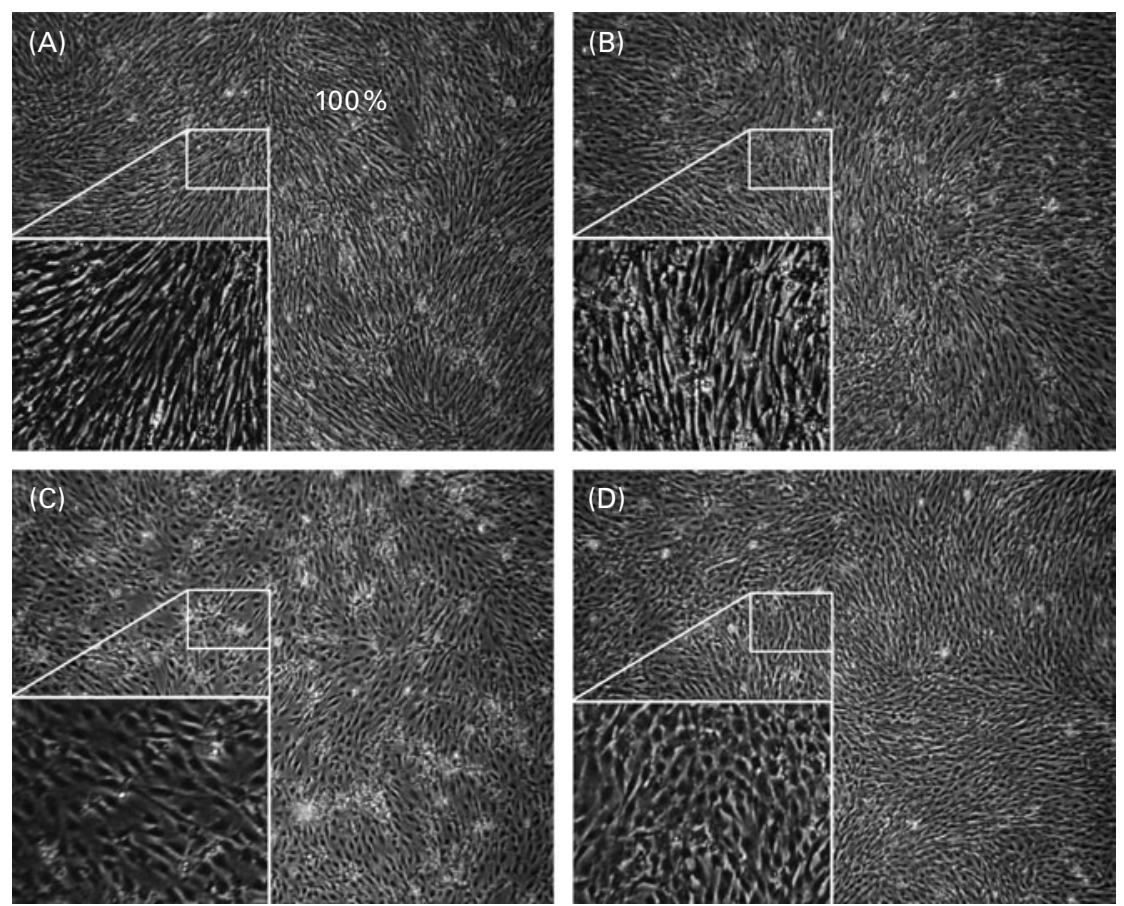

Fig. 1. Morphology of the differentiated $\mathrm{C} 2 \mathrm{C} 12$ myotube cells. (A) Control cells treated with deionised/distilled water; (B) cells treated with $1 \mu \mathrm{g} / \mathrm{ml}$ low-molecularweight fucoidan (LMWF); (C) cells treated with $10 \mu \mathrm{g} \mathrm{LMWF/ml;} \mathrm{(D)} \mathrm{cells} \mathrm{treated} \mathrm{with} 100 \mu \mathrm{g} \mathrm{LMWF} / \mathrm{ml}$. 


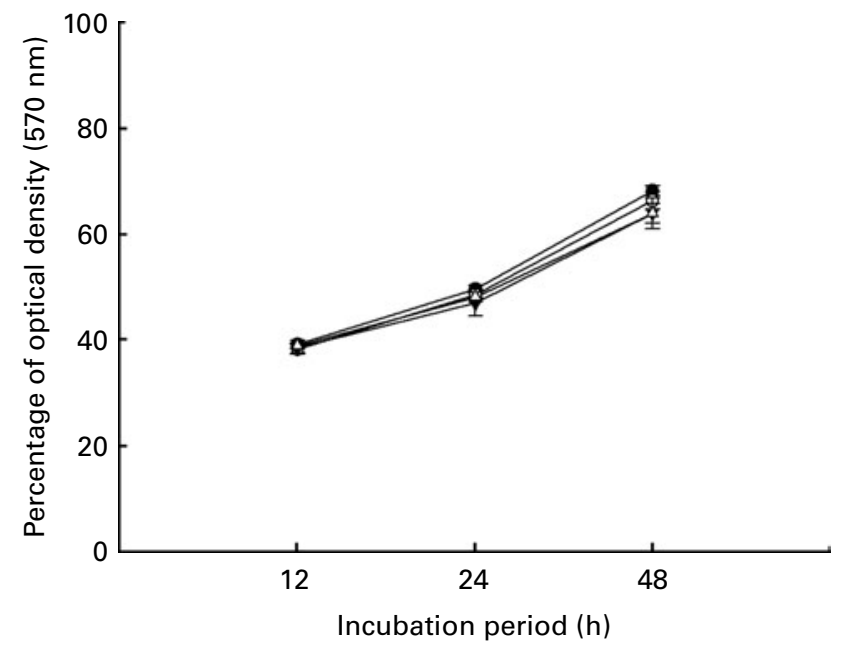

Fig. 2. Effects of low-molecular-weight fucoidan (LMWF) on the cell viability of $\mathrm{C} 2 \mathrm{C} 12$ myoblasts treated for 12,24 and $48 \mathrm{~h}$. Viability was determined using the sodium $3^{\prime}$-[1-[(phenylamino)-carbonyl]-3,4-tetrazolium]-bis (4-methoxy-6-nitro)benzene sulfonic acid hydrate assay. Values are means of five independent experiments, with standard deviations represented by vertical bars. -,$-- 0 \mu \mathrm{g} \mathrm{LMWF} / \mathrm{ml} ;-0-, 1 \mu \mathrm{g} \mathrm{LMWF} / \mathrm{ml} ;-\nabla-, 10 \mu \mathrm{g}$ $\mathrm{LMWF} / \mathrm{ml} ;-\Delta-, 100 \mu \mathrm{g} \mathrm{LMWF} / \mathrm{ml}$.

with the control cells. Additionally, the MRF 4 mRNA levels were decreased by approximately $7 \cdot 3,38.7$ and $56.4 \%$, respectively, compared with the control cells. Moreover, the reduced protein expression of myogenin, MEF2 and MyoD in $\mathrm{C} 2 \mathrm{C} 12$ cells paralleled the reduced mRNA expression levels in the presence of LMWF during differentiation.
Taken together, these results suggest that LMWF inhibited MyoD, as shown in Fig. 3.

\section{Effects of low-molecular-weight fucoidan on mitogen- activated protein kinase expression during myogenic differentiation}

To evaluate the effect of LMWF on the regulation of the MAPK pathways, we used RT-PCR to examine whether LMWF could activate p38 MAPK $\alpha$, ERK and JNK (Fig. 4(A)). Expression of the p38 MAPK $\alpha$ gene decreased upon treatment with LMWF in $\mathrm{C} 2 \mathrm{C} 12$ cells undergoing MyoD. We then investigated whether LMWF has a role in the inactivation of molecules downstream of p38 MAPK $\alpha$, such as ERK and JNK. LMWF reduced the expression of ERK and JNK during the MyoD of C2C12 cells. Treatment with 1, 10 and $100 \mu \mathrm{g}$ LMWF/ml decreased ERK by approximately $7 \cdot 0,53.2$ and $58.8 \%$, respectively, relative to the controls. Additionally, the JNK mRNA levels decreased by approximately $0 \cdot 6,23.75$ and $36 \cdot 4 \%$, respectively, compared with the controls. Furthermore, as shown in Fig. 4(B), an increase in LMWF concentration resulted in a further decrease in the phospho-ERK and phospho-JNK levels in C2C12 cells.

\section{Low-molecular-weight fucoidan represses key genes of myogenic differentiation better than heparin}

Because heparin inhibits myoblast differentiation ${ }^{(30)}$, we investigated the effect of both LMWF and heparin on

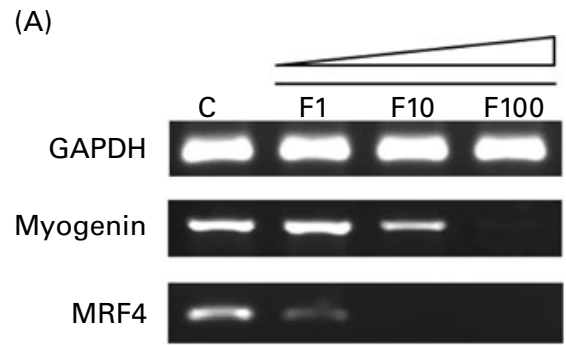

(C)

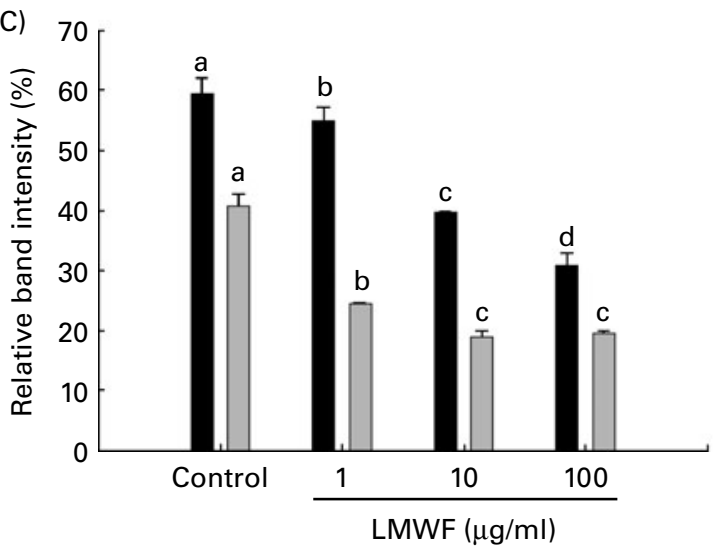

(B)

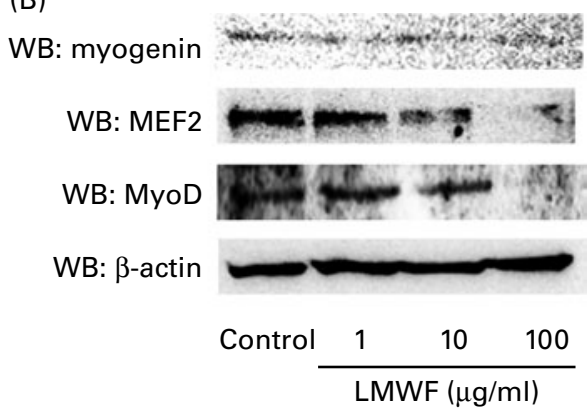

Fig. 3. Low-molecular-weight fucoidan (LMWF) suppressed key markers in C2C12 cells undergoing myogenic differentiation (MyoD). (A) mRNA expression of myogenin ( $\square$ ) and muscle regulatory factor 4 (MRF4, $\square$ ) in C2C12 cells. (B) Protein expression of myogenin, myocyte enhancer factor 2 (MEF 2) and MyoD in $\mathrm{C} 2 \mathrm{C} 12$ cells. Cells were cultured for $72 \mathrm{~h}$ with LMWF at concentrations of $0,1,10$ and $100 \mu \mathrm{g} / \mathrm{ml}$. Values are means of three replicates, with standard deviations represented by vertical bars. ${ }^{a, b, c, d}$ Mean values with unlike letters were significantly different within each treatment group $(P<0 \cdot 05)$. C, control; $\mathrm{F}$, fucoidan; GAPDH, glyceraldehyde 3-phosphate dehydrogenase; WB, Western blotting. 
(A)

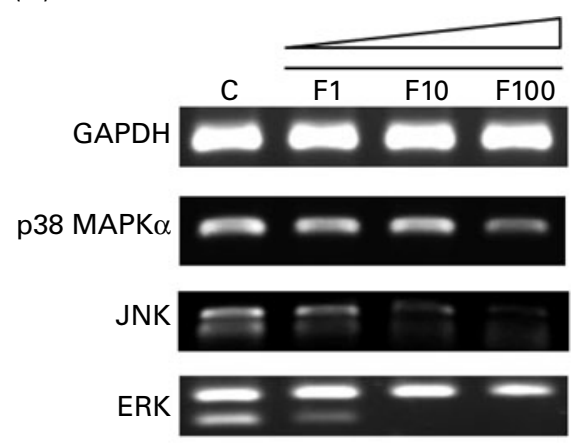

(C)

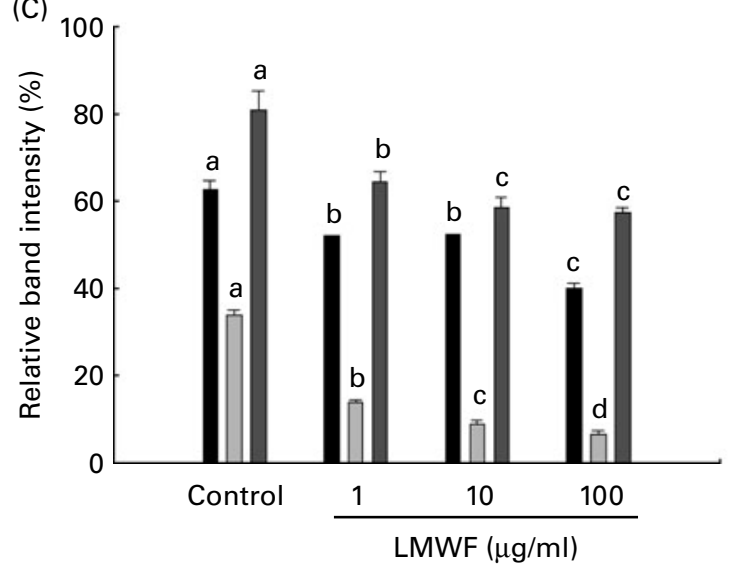

(B)

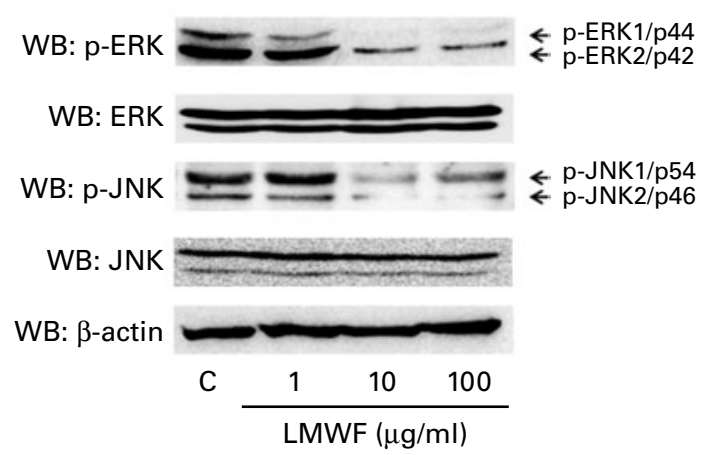

Fig. 4. Low-molecular-weight fucoidan (LMWF) suppressed the expression of mitogen-activated protein kinase (MAPK) expression in C2C12 cells undergoing myogenic differentiation. (A) LMWF inhibited the mRNA expression of p38 MAPK $\alpha(\boldsymbol{\square})$, extracellular-regulated kinase (ERK, $\square)$ and Jun $\mathrm{NH}_{2}$-terminal kinase (JNK, ם) in C2C12 cells undergoing myogenic differentiation. (B) Phospho-ERK (p-ERK) and phospho-JNK (p-JNK) protein expression was inhibited in a dose-dependent manner by LMWF in C2C12 cells. Cells were cultured for $72 \mathrm{~h}$ with $0,1,10$ and $100 \mu \mathrm{g} \mathrm{LMWF} / \mathrm{ml}$. Values are means of three replicates, with standard deviations represented by vertical bars. ${ }^{a, b, c, d}$ Mean values with unlike letters were significantly different within each treatment group $(P<0.05)$. C, control; F, fucoidan; GAPDH, glyceraldehyde 3-phosphate dehydrogenase; WB, Western blotting.

myogenesis. Heparin alone was used as a positive/negative control. MRF4 and myogenin are both important MyoD markers that are crucial for muscle development, and both were examined. LMWF and heparin were given alone and in combination during differentiation for a total of $4 \mathrm{~d}$. MRF 4 and myogenin mRNA expression showed that the patterns were statistically significant. The expression of both genes was decreased in the $100 \mu \mathrm{g} \mathrm{LMWF} / \mathrm{ml}$ treatment group compared with the untreated group. Decreased gene expression was also observed after the treatment with $10 \mu \mathrm{g}$ heparin $/ \mathrm{ml}$ (Fig. 5). The LMWF-heparin combination treatment group showed a decrease in the gene expression of MRF4 and myogenin.

\section{Effects of low-molecular-weight fucoidan and heparin- mediated mitogen-activated protein kinase gene expression on myogenic differentiation}

We then investigated whether treatment with LMWF and heparin leads to the inactivation of molecules downstream of p38 MAPK $\alpha$, such as ERK and JNK. LMWF and heparin reduced the mRNA expression of ERK and JNK during myogenesis. During MyoD, C2C12 cells were treated with $100 \mu \mathrm{g}$ LMWF/ml and/or $10 \mu \mathrm{g}$ heparin/ml. Fig. 6 illustrates that the mRNA expression of p38 MAPK $\alpha$, ERK and JNK was significantly decreased upon treatment with LMWF and heparin in combination. There was a strong repression of these genes compared with the control group. Interestingly, the ERK mRNA levels decreased more when treated with LMWF alone than in combination with heparin.

\section{Response of antioxidant enzymes}

After the cells were treated with LMWF and/or heparin for $4 \mathrm{~d}$, the mRNA expression levels of MnSOD, catalase, glutathione peroxidase and glutathione reductase decreased significantly in the LMWF and/or heparin groups compared with the control group (Fig. 7(A) and (B)). These data showed that treatment with LMWF inhibited the expression of MnSOD, catalase and glutathione peroxidase better than treatment with heparin alone. The expression levels of these genes after the LMWF and combination treatments (LMWF and heparin) were repressed to levels significantly below those of the control group. Although a significant reduction in gene expression was also observed in the group treated with heparin alone, LMWF more strongly repressed antioxidant-related gene expression. Glutathione reductase expression was found to be significantly decreased in the LMWF, heparin and combination treatment groups. 
(A)

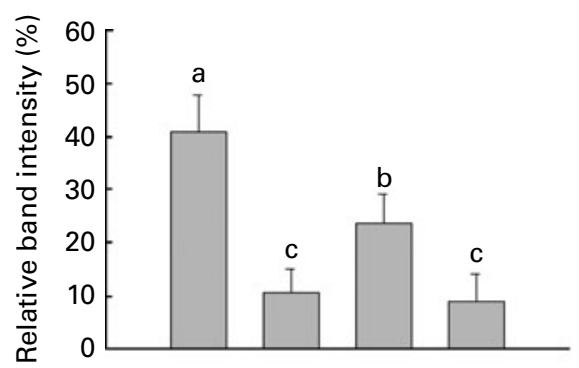

GAPDH

MRF4

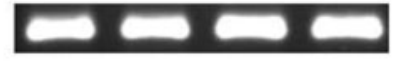

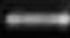

(B)
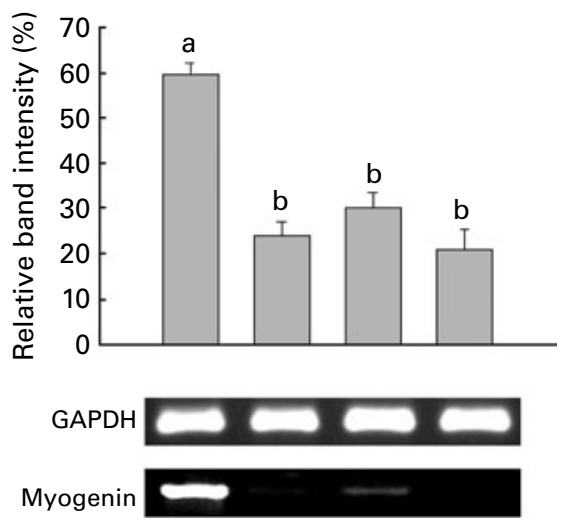

Myogenin

Fig. 5. Low-molecular-weight fucoidan (LMWF) and heparin suppressed the mRNA expression of (A) muscle regulatory factor 4 (MRF4) and (B) myogenin in $\mathrm{C} 2 \mathrm{C} 12$ cells undergoing myogenic differentiation. LMWF and heparin were used in combination to treat $\mathrm{C} 2 \mathrm{C} 12$ cells. Values are means of three replicates, with standard deviations represented by vertical bars. ${ }^{a, b, c}$ Mean values with unlike letters were significantly different within each treatment group $(P<0 \cdot 05)$. GAPDH, glyceraldehyde 3-phosphate dehydrogenase.

\section{Discussion}

Fucoidan, a sulfated polysaccharide, is primarily extracted from brown seaweeds. Fucoidan has been broadly studied in recent years due to its numerous biological properties. Additionally, the biological activities of different fucoidan species have been reported to be closely related to both the sulfate content and the molecular weight ${ }^{(31)}$. Due to these characteristics of fucoidan, we hydrolysed it to produce LMWF, as described in the Materials and methods section, and examined the biological properties of LMWF.

We examined the effects of LMWF on the differentiation of myoblasts. Previously, we showed that LMWF is mainly composed of carbohydrates (58.2\%) and sulfate (35.5\%) with a small amount of protein $(1 \cdot 2 \%)^{(32)}$. These previous measurements are in agreement with other studies, which indicated that LMWF from other brown seaweeds has comparable amounts (42-66\%) of carbohydrates but smaller amounts of sulfate (11.5-30.0\%) and a protein content that varies from 0 to $12 \%^{(33,34)}$.

The development of muscle in somites is a multistep process in which pluripotent mesodermal cells become committed to the myogenic lineage by receiving signals from neighbouring tissues. These signals initiate the expression of transcription factors from the MRF family, specifically MyoD and MRF4, in cells that differentiate into myoblasts. Subsequently, the activities of MyoD and MRF4 are induced, which leads to the withdrawal of myoblasts from the cell cycle. Additionally, MyoD initiates the expression of other transcription factors from the MEF2 family and myogenin.
(A)

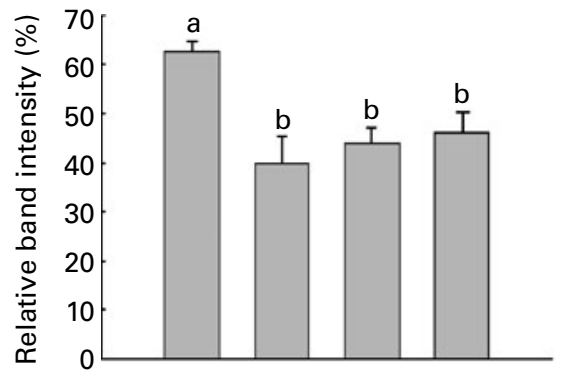

GAPDH

p38 MAPK

Heparin $10 \mu \mathrm{g} / \mathrm{m}$
(B)
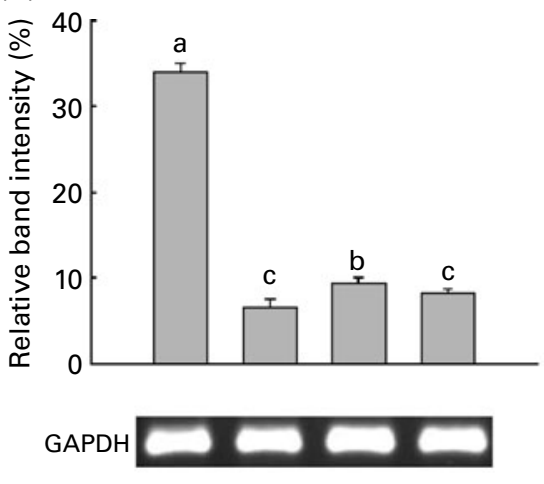

(C)
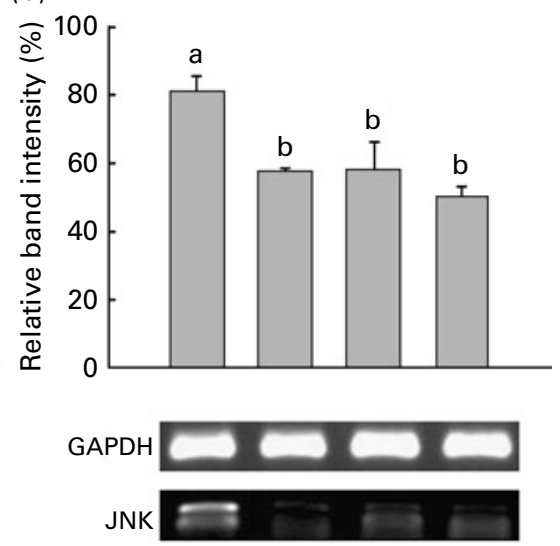

\section{ERK}

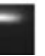

Heparin $10 \mu \mathrm{g} / \mathrm{ml}$

LMWF $100 \mu \mathrm{g} / \mathrm{m}$

Heparin $10 \mu \mathrm{g} / \mathrm{ml}$

+ Fucoidan $100 \mu \mathrm{g} / \mathrm{ml}$ -

Fig. 6. Low-molecular-weight fucoidan (LMWF) and heparin suppressed the mRNA expression of (A) p38 mitogen-activated protein kinase $\alpha$ (p38 MAPK $\alpha$ ), (B) extracellular-regulated kinase (ERK) and (C) Jun $\mathrm{NH}_{2}$-terminal kinase (JNK) in C2C12 cells undergoing myogenic differentiation. LMWF and heparin were used in combination to treat $\mathrm{C} 2 \mathrm{C} 12$ cells. Values are means of three replicates, with standard deviations represented by vertical bars. ${ }^{\text {a,b,c }}$ Mean values with unlike letters were significantly different within each treatment group $(P<0.05)$. GAPDH, glyceraldehyde 3-phosphate dehydrogenase. 
(A)

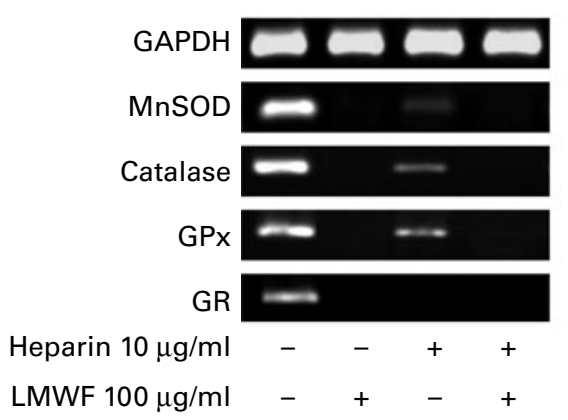

(B)

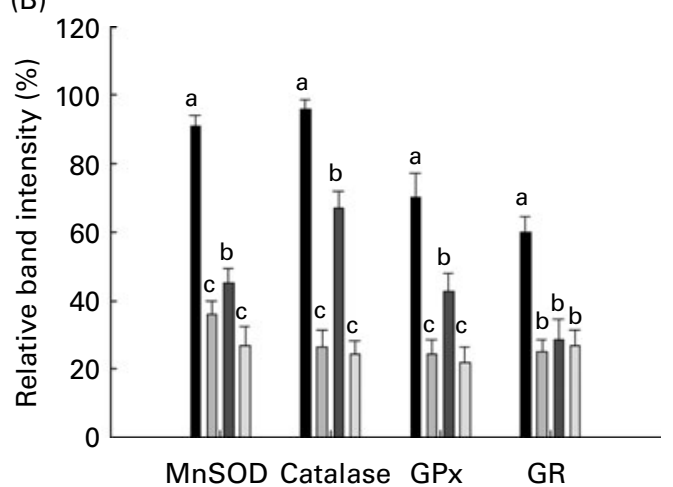

Fig. 7. Semi-quantitative RT-PCR was performed on (A) the Mn superoxide dismutase (MnSOD), catalase, glutathione peroxidase (GPx) and glutathione reductase (GR) mRNA transcripts in (B) the control ( $\mathbf{a})$, low-molecular-weight fucoidan (LMWF, $100 \mu \mathrm{g} / \mathrm{ml}$; $\square$ ), heparin (10 $\mu \mathrm{g} / \mathrm{ml}$; $\square$ ) and LMWF-heparin combination ( $\square$ ) treatment groups. Values are means of three replicates, with standard deviations represented by vertical bars. ${ }^{\text {a,b,c }}$ Mean values with unlike letters were significantly different $(P<0.05$, Duncan's multiple test). GAPDH, glyceraldehyde 3-phosphate dehydrogenase.

Together, myogenin and MEF2 family members cooperate in the activation of many structural muscle genes during differentiation. The present study showed that LMWF strongly inhibited MyoD by markedly decreasing the mRNA expression of MRF4 and myogenin, as well as MyoD, myogenin and MEF2 protein expression. Moreover, LMWF inhibited myotube formation.

Of the four isoforms of $\mathrm{p} 38$ ( $\alpha, \beta, \gamma$ and $\delta$ ), the phosphorylation and activity of the $\alpha$ and $\beta$ isoforms are gradually induced during the differentiation of myoblasts ${ }^{(35,36)}$. The p38 pathway is essential for both the activation of the MyoD-dependent promoter and the MyoD-mediated conversion of myoblasts to myogenic cells, which suggests the possibility that MyoD might also be a target of p38. Penn et al. ${ }^{(37)}$ demonstrated that p38 MAPK $\alpha$ expression regulated the formation of a MyoD-MEF2 complex at a set of late promoters. The ERK pathway has also been implicated in the positive control of myogenesis ${ }^{(28)}$. However, another report has proposed a negative regulatory function ${ }^{(38)}$. The concomitant decline in ERK activity and the stimulation of p38 MAPK $\alpha$ during the early phase of terminal differentiation may facilitate a reduction in cyclin $\mathrm{D} 1^{(39)}$, thereby leading to the activation of MyoD ${ }^{(40)}$ and other MyoD markers. Consistent with these reports, the present data show that p38 MAPK $\alpha$ controls the MyoD of skeletal muscle cells, and the expression of muscle differentiation markers is down-regulated by inhibiting the p38 MAPK $\alpha$ pathway. Some researchers have suggested that JNK controls ERK-mediated myogenic activity ${ }^{(41)}$, while another report has proposed that JNK is not essential for the inhibition of muscle differentiation ${ }^{(42)}$. The results of the present study show that LMWF suppresses the phosphorylation of JNK in C2C12 myoblasts. The p38 MAPK $\alpha$ pathways have been previously demonstrated to be oxidant-sensitive in vascular smooth muscle cells with preferential activation of $\mathrm{p} 38 \mathrm{MAPK} \alpha^{(15,43)}$. Indeed, the increase in ROS is partially responsible for muscle differentiation. Here, we showed that LMWF suppresses the mRNA and protein expression of p38 MAPK as well as ROS-related transcription factors in myogenesis. Although we have shown that ROS are related to the transcription level, further experiments are needed to define the relationship of MyoD and ROS. A previous report has shown that myostatin inhibits myoblast differentiation by down-regulating MyoD $^{(44)}$. This result indicated that LMWF might regulate MyoD through the p38 MAPK $\alpha$ pathway by regulating ROS activity.

Heparin exerts a pronounced inhibitory effect on muscle growth in vitro, as determined by total protein, and myosin accumulation $^{(45)}$. It has been shown that heparin not only prevented MAPK activation ${ }^{(46)}$ but also reduced ROS production $^{(47)}$. In the present study, we have shown that heparin suppressed MyoD marker (Fig. 5). Inhibition of the MAPK pathway and ROS-related gene expression is also shown in Figs. 6 and 7. Interestingly, these results showed a more strong inhibition of MyoD through the repression of MAPKrelated gene expression and ROS generation by LMWF.

In conclusion, the present study showed a part of the mechanism of how LMWF regulates the myogenesis of C2C12 cells. The data obtained in the present study suggest for the first time that LMWF suppressed MyoD through the p38 MAPK pathway and a ROS-related transcription factor better than heparin, suggesting that LMWF might have an interesting effect on muscle differentiation.

\section{Acknowledgements}

The present study was supported by both the project titled 'Development of lipid lowering food and drug biomaterials with Korean seaweed' funded by the Ministry of Land, Transport and Maritime Affairs, Korea and grant no. RTI 05-01-02 from the Regional Technology Innovation Program of the Ministry of Knowledge Economy. K.-J. K. contributed to the experimental design, experimental procedures, data interpretation and manuscript writing. O.-H. L. gave an important contribution to the experimental procedures. B.-Y. L. contributed to the experimental procedures, data analysis, data interpretation and manuscript writing. All authors contributed to the critical revision of the manuscript. The authors declare that there are no conflicts of interest. 


\section{References}

1. Herskowitz I (1995) MAP kinase pathways in yeast: for mating and more. Cell 80, 187-197.

2. Hill CS \& Treisman R (1995) Transcriptional regulation by extracellular signals: mechanisms and specificity. Cell 80, 199-211.

3. Robinson MJ \& Cobb MH (1997) Mitogen-activated protein kinase pathways. Curr Opin Cell Biol 9, 180-186.

4. Lluis F, Perdiguero E, Nebreda AR, et al. (2006) Regulation of skeletal muscle gene expression by p38 MAP kinases. Trends Cell Biol 16, 36-44.

5. Keren A, Tamir Y \& Bengal E (2006) The p38 MAPK signaling pathway: a major regulator of skeletal muscle development. Mol Cell Endocrinol 252, 224-230.

6. Bandyopadhyay GK, Yu JG, Ofrecio J, et al. (2005) Increased p85/55/50 expression and decreased phosphotidylinositol 3-kinase activity in insulin-resistant human skeletal muscle. Diabetes 54, 2351-2359.

7. Braun T, Buschhausen-Denker G, Bober E, et al. (1989) A novel human muscle factor related to but distinct from MyoD1 induces myogenic conversion in 10T1/2 fibroblasts. EMBO J 8, 701-709.

8. Gossett LA, Kelvin DJ, Sternberg EA, et al. (1989) A new myocyte-specific enhancer-binding factor that recognizes a conserved element associated with multiple muscle-specific genes. Mol Cell Biol 9, 5022-5033.

9. Edmondson DG \& Olson EN (1989) A gene with homology to the myc similarity region of MyoD1 is expressed during myogenesis and is sufficient to activate the muscle differentiation program. Genes Dev 3, 628-640.

10. Janower ML (1993) Proposal for a shared resource in clinical diagnostic radiology research. Radiology 186, 581.

11. Chiarugi P, Pani G, Giannoni E, et al. (2003) Reactive oxygen species as essential mediators of cell adhesion: the oxidative inhibition of a FAK tyrosine phosphatase is required for cell adhesion. J Cell Biol 161, 933-944.

12. Gupta A, Rosenberger SF \& Bowden GT (1999) Increased ROS levels contribute to elevated transcription factor and MAP kinase activities in malignantly progressed mouse keratinocyte cell lines. Carcinogenesis 20, 2063-2073.

13. Klotz LO, Pellieux C, Briviba K, et al. (1999) Mitogenactivated protein kinase (p38-, JNK-, ERK-) activation pattern induced by extracellular and intracellular singlet oxygen and UVA. Eur J Biochem 260, 917-922.

14. Kim KJ, Lee OH, Lee HH, et al. (2010) A 4-week repeated oral dose toxicity study of fucoidan from the Sporophyll of Undaria pinnatifida in Sprague-Dawley rats. Toxicology 267, 154-158.

15. Su B, Mitra S, Gregg H, et al. (2001) Redox regulation of vascular smooth muscle cell differentiation. Circ Res 89, 39-46.

16. Beress A, Wassermann O, Tahhan S, et al. (1993) A new procedure for the isolation of anti-HIV compounds (polysaccharides and polyphenols) from the marine alga Fucus vesiculosus. J Nat Prod 56, 478-488.

17. Pereira MS, Mulloy B \& Mourao PA (1999) Structure and anticoagulant activity of sulfated fucans. Comparison between the regular, repetitive, and linear fucans from echinoderms with the more heterogeneous and branched polymers from brown algae. J Biol Chem 274, 7656-7667.

18. Koyanagi S, Tanigawa N, Nakagawa H, et al. (2003) Oversulfation of fucoidan enhances its anti-angiogenic and antitumor activities. Biochem Pharmacol 65, 173-179.

19. Preeprame S, Hayashi K, Lee JB, et al. (2001) A novel antivirally active fucan sulfate derived from an edible brown alga, Sargassum horneri. Chem Pharm Bull (Tokyo) 49, 484-485.
20. Bochkov VN, Tkachuk VA, Philippova MP, et al. (1996) Ligand selectivity of $105 \mathrm{kDa}$ and $130 \mathrm{kDa}$ lipoproteinbinding proteins in vascular-smooth-muscle-cell membranes is unique. Biochem J 317, Pt 1, 297-304.

21. Lee JB, Hayashi K, Hashimoto M, et al. (2004) Novel antiviral fucoidan from sporophyll of Undaria pinnatifida (Mekabu). Chem Pharm Bull (Tokyo) 52, 1091-1094.

22. Patankar MS, Oehninger S, Barnett T, et al. (1993) A revised structure for fucoidan may explain some of its biological activities. J Biol Chem 268, 21770-21776.

23. Nishino T, Aizu Y \& Nagumo T (1991) Antithrombin activity of a fucan sulfate from the brown seaweed Ecklonia kurome. Thromb Res 62, 765-773.

24. Religa P, Kazi M, Thyberg J, et al. (2000) Fucoidan inhibits smooth muscle cell proliferation and reduces mitogenactivated protein kinase activity. Eur J Vasc Endovasc Surg 20, 419-426.

25. Berteau O \& Mulloy B (2003) Sulfated fucans, fresh perspectives: structures, functions, and biological properties of sulfated fucans and an overview of enzymes active toward this class of polysaccharide. Glycobiology 13, 29R-40R.

26. Kim KJ, Lee OH \& Lee BY (2010) Genotoxicity studies on fucoidan from Sporophyll of Undaria pinnatifida. Food Chem Toxicol 48, 1101-1104.

27. Nardella A, Chaubet F, Boisson-Vidal C, et al. (1996) Anticoagulant low molecular weight fucans produced by radical process and ion exchange chromatography of high molecular weight fucans extracted from the brown seaweed Ascophyllum nodosum. Carbohydr Res 289, 201-208.

28. Gredinger E, Gerber AN, Tamir Y, et al. (1998) Mitogenactivated protein kinase pathway is involved in the differentiation of muscle cells. J Biol Chem 273, 10436-10444.

29. Roehm NW, Rodgers GH, Hatfield SM, et al. (1991) An improved colorimetric assay for cell proliferation and viability utilizing the tetrazolium salt XTT. I Immunol Methods 142, 257-265.

30. Fuentealba L, Carey DJ \& Brandan E (1999) Antisense inhibition of syndecan-3 expression during skeletal muscle differentiation accelerates myogenesis through a basic fibroblast growth factor-dependent mechanism. J Biol Chem $\mathbf{2 7 4}$, 37876-37884.

31. Qiu X, Amarasekara A \& Doctor V (2006) Effect of oversulfation on the chemical and biological properties of fucoidan. Carbohydr Polym 63, 224-228.

32. You S, Yang C, Lee H, et al. (2010) Molecular characteristics of partially hydrolyzed fucoidans from sporophyll of Undaria Pinnatifida and their in vitro anticancer activity. Food Chem 119, 554-559.

33. Bilan MI, Grachev AA, Shashkov AS, et al. (2006) Structure of a fucoidan from the brown seaweed Fucus serratus L. Carbobydr Res 341, 238-245.

34. Ponce NM, Pujol CA, Damonte EB, et al. (2003) Fucoidans from the brown seaweed Adenocystis utricularis: extraction methods, antiviral activity and structural studies. Carbohydr Res 338, 153-165.

35. Cuenda A \& Cohen P (1999) Stress-activated protein kinase$2 /$ p38 and a rapamycin-sensitive pathway are required for C2C12 myogenesis. J Biol Chem 274, 4341-4346.

36. Wu Z, Woodring PJ, Bhakta KS, et al. (2000) p38 and extracellular signal-regulated kinases regulate the myogenic program at multiple steps. Mol Cell Biol 20, 3951-3964.

37. Penn BH, Bergstrom DA, Dilworth FJ, et al. (2004) A MyoDgenerated feed-forward circuit temporally patterns gene expression during skeletal muscle differentiation. Genes Dev 18, 2348-2353. 
38. Coolican SA, Samuel DS, Ewton DZ, et al. (1997) The mitogenic and myogenic actions of insulin-like growth factors utilize distinct signaling pathways. $J$ Biol Chem 272, 6653-6662.

39. Lavoie JN, L'Allemain G, Brunet A, et al. (1996) Cyclin D1 expression is regulated positively by the p42/p44MAPK and negatively by the p38/HOGMAPK pathway. $J$ Biol Chem 271, 20608-20616.

40. Skapek SX, Rhee J, Spicer DB, et al. (1995) Inhibition of myogenic differentiation in proliferating myoblasts by cyclin D1-dependent kinase. Science 267, 1022-1024.

41. Mauro A, Ciccarelli C, De Cesaris P, et al. (2002) PKCalphamediated ERK, JNK and p38 activation regulates the myogenic program in human rhabdomyosarcoma cells. $J$ Cell Sci 115, 3587-3599.

42. Gallo R, Serafini M, Castellani L, et al. (1999) Distinct effects of Rac1 on differentiation of primary avian myoblasts. Mol Biol Cell 10, 3137-3150.
43. Ushio-Fukai M, Alexander RW, Akers M, et al. (1998) p38 Mitogen-activated protein kinase is a critical component of the redox-sensitive signaling pathways activated by angiotensin II. Role in vascular smooth muscle cell hypertrophy. J Biol Chem 273, 15022-15029.

44. Langley B, Thomas M, Bishop A, et al. (2002) Myostatin inhibits myoblast differentiation by down-regulating MyoD expression. J Biol Chem 277, 49831-49840.

45. Kardami E, Spector D \& Strohman RC (1988) Heparin inhibits skeletal muscle growth in vitro. Dev Biol 126, 19-28.

46. Daum G, Hedin U, Wang Y, et al. (1997) Diverse effects of heparin on mitogen-activated protein kinase-dependent signal transduction in vascular smooth muscle cells. Circ Res 81, 17-23.

47. Dzieciuchowicz L, Checinski P \& Krauss H (2002) Heparin reduces oxidative stress in the postoperative period. Med Sci Monit 8, CR657-CR660. 